$\therefore$

NASA Technical Memorandum 104551

\title{
An Initial Analysis of the Data From the Polar Orbiting Geophysical (POGS) Satellite
}

R,A. Langel, T.J. Sabaka, and R.T. Baldwin

November 1991

(NASA-TM-104551) AN INITIAL ANALYSIS OF THE DATA FROM THE POLAR ORBITING GEOPHYSICAL (POGS) SATELLITE (NASA) 23 P

$$
\text { CSCL OBG }
$$

N92-13507 
13 
NASA Technical Memorandum 104551

\section{An Initial Analysis of the Data From the Polar Orbiting Geophysical (POGS) Satellite}

R.A. Langel

Goddard Space Flight Center

Greenbelt, Maryland

T.J. Sabaka and R.T. Baldwin

ST Systems Corporation

Lanham, Maryland

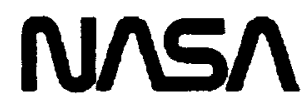

National Aeronautics and

Space Administration

Goddard Space Flight Center

Greenbelt, MD 


\begin{abstract}
The POGS (Polar Orbiting Geophysical Satellite) was launched in 1990 to measure the geomagnetic fleld. POGS data from selected magnetically quiet days was selected and quality checked and deleted where thought to be erroneous. A time and position correction was applied. The resulting data was fit to a degree 13 spherical harmonic model. Evaluation of the quality of the data indicates that it is sufficient for definition of the low degree (say, less than 8 ) portion of the geomagnetic field. Further correction of the data time and position may improve this quality.
\end{abstract}




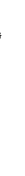


INTRODUCTION

POGS (Polar Orbiting Geophysical Satellite), a project of the Naval Oceanographic Office (NOO), was launched by an Atlas E rocket from Vandenberg Air Force base in April of 1990 into a circular polar orbit of approximately $800 \mathrm{~km}$ at an inclination of $89.5^{\circ}$. The satelite was equipped with a vector fluxgate magnetometer mounted on an eight foot earth-pointing boom. Each axis of the instrument has a range of $\pm 65535 \mathrm{nT}$ with a resolution of $2 \mathrm{nT}$. No absolute instrument was carried to correct for instrument drift, and the vector attitude information was insufficient for attitude corrections of the accuracy required for solid Earth geophysical applications. The instrument drift rate was supposed to be no greater than $50 \mathrm{nT} / \mathrm{yr}$ (Acuna, personal communication) and the attitude accuracy is thought to be about $0.5^{\circ}$ to $1.0^{\circ}$. POGS is stabilized by the gravity gradient method and because of deployment problems, was injected into orbit upside down. This caused problems with the solar panels (i.e., power) and telemetry antenna. Although the latter problem has currently been worked around by reconfiguring the transmission and reception pattern of the ground station tracking, the data used in this study suffers from large gaps. A more severe problem concerns the magnetometer clock. The accuracy of its correspondence to GMT is in error by as much as 5.5 seconds. Correcting this problem is discussed in the following section. 
The preliminary POGS data set was provided to us by John Quinn of the Noo. From the provided data, passes were chosen during days which were relatively magnetically quiet, as detemined from preliminary $\mathrm{Kp}$ values. For this initial study, no further attempt was made to eliminate magnetically disturbed data. The selected days, the three hourly kp index, and the number of observations selected are shown in Table 1 . Figure 1 shows the geographic distribution of the resulting data.

The method used for correction of data time with UT was not properly functioning during 1990 but was made operable in January of 1991. Since the presently considered data are from 1990, the assigned time can be in error by several seconds. Rough estimates of the required time corrections were supplied along with the inftial data by Noo. These corrections were determined by NOO using a trial and error procedure in which, for selected days, spherical harmonic models were derived using a suite of time offsets. The offset resulting in the lowest residuals (i.e., best fit) to the data was considered to be the time correction needed. The process was complicated by the fact that the answer was bi-modal, 1.e. there were two times giving a minimum in the residuals. The selected time was taken to be midway between the two minima. 
The resulting corrections estimate the magnetometer - ephemeris time offset In seconds for thirteen days between Jullan day 152 and 257. Time offsets ranged from 5.5 to -0.6 seconds for these days. Coefficients for a quadratic function were computed from the time correction information and were used to determine the appropriate time shift for each observation. Figure 2 shows the corrections and the fitted quadratic function.

Satellite positions at the revised data times were then computed and appended to the observations. This was accomplished by calculating $X, Y$, and 2 velocities from the ephemeris data and using these together with the time correction offsets to compute corrected positions. The entire procedure is very ad hoc.

EVALUATION

Residual POGS data were plotted for each of the quiet days after removing the GSFC(8/91) model as shown in Figure 3 . This model is fit to the POGS data itself, as described in a later section. The quality of the data is suspect owing to the long-wavelength features (about $21000 \mathrm{~km}$ wavelength) which are approximately equal to one half orbit. It is presently assumed that this feature is a function of the satellite - ephemeris time offset since the time correction given by NoO was preliminary. 
Poor attitude control and lack of an absolute instrument alone preclude the use of the POGS satellite vector magnetometer data in solid Earth geophysical applications. However, scalar (B) data computed from the observed vector measurements may be of use since they are independent of orientation. In order to ensure quality, the scalar data were assessed with respect to a field model and the accepted residuals were then assessed with respect to a B-spline function. This evaluation was performed via a program, called FILTER, originally designed for DMSP satellite processing (Ridgway et al., 1989; Langel et al., 1990).

Specifically, FILTER evaluated the data in 86400 second (one day) pieces, hence each quiet day was processed independently. Table 1 shows the date, the Kp Three-Hourly indices, and the number of measurements for each of the 13 quiet days used. The first task was to compute scalar residuals $(\Delta B)$ from a field model and then flag as outliers points with residual magnitudes exceeding $1000 \mathrm{nT}$. Flagged measurements were excluded from further analysis. The field model used was the United States Geological Survey (USGS) 1990 IGRF candidate main field model, including the secular variation estimation for 1990-1995. This model is of degree 10 in its internal field spherical harmonic expansion and of degree 8 in its secular variation terms. 
The second task was to fit a cubic B-spline, with internal knots every 100 seconds, to the accepted $\Delta B$. The times of the earliest and latest accepted data point served as external knot positions. The B-spline scaling factors were determined via an unweighted least-squares estimator. Those measurements whose B-spline residual magnitude was found to be greater than twice the rms of the B-spline fit were flagged and excluded from further analysis. The number of measurements remaining for each day after the evaluation are shown in Table 2 .

COMPARISON WITH FIELD MODELS

As a preliminary method of assessing the data quality, it was compared with the candidate IGRF models for 1990. These models are summarized in Table 3. The statistics to each model are given in Table 4.

A FIRST MODEL FIT TO THE POGS DATA

Since the goal is to determine the validity of the POGS satellite magnetometer data in main field modeling, it is logical to calculate the best fit model with the culled data. A degree 13 internal spherical harmonic expansion was determined by the POGS B data. This model is denoted as GSFC(8/91) and is given in Table 5. The USGS 1990 IGRF candidate model was used as a starting model and its secular variation 
terms used to reduce the data to 1990 . The mean radius of the Earth's is taken to be $6371.2 \mathrm{~km}$ with a flattening factor of $1 / 298.25$. The model was determined by a weighted least-squares estimator, which was iterated 4 times. The scalar data was assigned a uniform uncertainty of $25 \mathrm{nT}$.

The residual mean and sigma with respect to GSFC(8/91) for the data from each of the 13 quiet days as well as collectively are listed in Table 2 . The weighted residual varlance suggests a calibration factor of 1.4 for the GSFC(8/91) covariance matrix, which would increase the data uncertainty from 25 to $29.6 \mathrm{nT}$ in accordance with the overall residual sigma (see Table 2).

Figure 4 shows a plot of the quantity $R_{n}$, defined as the total mean square over the Earth's surface of the magnetic field intensity produced by hamonics of the $n$ 'th degree. $R_{n}$ is given by

$$
R_{n}=(n+1) \sum_{m=0}^{n}\left[\left(g n^{m}\right)^{2}+\left(h_{n} m\right)^{2}\right]
$$

For comparison, the plot also shows $R_{n}$ from the degree 23 MGST(10/81) model (Langel and Estes, 1982) based on Magsat data. At degrees where the amplitude of $R_{n}$ from GSFC(8/91) exceeds that from MGST(10/81) it is Iikely that GSFC(8/91) is contaminated by some noise source. This is particularly evident at and above degree 8 and, to a lesser extent, degree 6 . 
Table 6 shows the coefficient by coefficient differences between GSFC $(8 / 91)$ and IGRF 1990 (IAGA, 1991). Note that this is a different field model than that used in the data cleanup process.

\section{CONCLUSIONS}

This study must be regarded as very preliminary if for no other reason than the uncertainty in the sssigned times, and hence positions, of the data. Nevertheless it gives indication that the POGS data is of acceptable quality for modeling the low degree ( $n<9$, at least) terms in the geomagnetic field.

Possible drift in instrument calibration will always be a question for this data. Fluxgate magnetometers are not absolute instruments and are known to drift with time. For example, there was an apparent, though small, drift in the Magsat vector data (Langel et al., 1981) which was detected and adjusted for by comparison with an absolute scalar instrument. POGS has no such absolute instrument. Similarly, no absolute instrument was present on the DE-2 spacecraft. Langel et al. (1988) describe a comparison of the DE2 data with co-temporaneous surface data to attempt to detect any shifts, biases, etc. In the DE-2 data. Very small adjustments were made and an apparently reasonable field model produced. When final time corrections are available, and when sufficient co-temporaneous surface data are available, such an assessment of the POGS data would be useful. 
Even if no apparent drift is detected, its possible presence will always be an open question. There is simply no way to be certain regarding its presence or absence. This implies a, hopefully small, degree of uncertainty in temporal change models incorporating the POGS data. An upper bound for this uncertainty is not yet available.

A follow-on POGS mission is under consideration in combination with the DMSP series of spacecraft. In particular, a fluxgate magnetometer is planned to be located at the end of a $5 \mathrm{~m}$ boom on a future DMSP mission. Data from such a configuration would be greatly enhanced over POGS I and over prefious DMSP data. Such data would benefit from the excellent DMSP attitude detemination and would undoubtedly be free from the timing and telemetry problems experienced with POGS I. The boom should effectively eliminate the spacecraft field noise experienced on prior DMSP missions.

\section{ACKNOWLEDGEMENTS}

We are grateful to John Quinn for supplying the POGS data and the "rough" time correction and for valuable discussion. This work was jointly funded by the Phillips laboratory of the US Air Force (formerly AFGL) and by NASA RTOP 539-31-02. 


\section{REFERENCES}

IAGA Division $V$ Working Group 8, International Geomagnetic Reference Field, 1991 Revision, Eos, Trans. AGU, submitted, 1991.

Langel, R.A. and R.H. Estes, A geomagnetic field spectrum, Geophys. Res. Lettr., $9,254-257,1982$.

Langel, R.A., J. Berbert, T. Jennings, and R. Horner, Magsat data processing: A report for investigators, NASA TM 82160, November, 1981.

Langel, R.A., J.R. Ridgway, M. Sugiura, and R. Maezawa, The geomagnetic field at 1982 from $D E-2$ and other magnetic field data, J. Geomag. Geoelectr. , 40, 1103-1127, 1988.

Langel, R.A., T.J. Sabaka, and J.R. Ridgway, Processing of DMSP magnetic data: Handbook of programs, tapes and datasets, NASA TM 100757, February, 1990.

Ridgway, J.R., T.J. Sabaka, D. Chinn, and R.A. Langel, Processing of DMSP data and its use in geomagnetic field modeling. NASA TM 100750. November, 1989. 
TABLE 1: QUIET DAYS SELECTED AND NUMBER OF DATA AVAILABLE

\begin{tabular}{lllllllllllll} 
& \multicolumn{1}{c}{ Rp Three-HourIy Indices } & Number of & Local Time of \\
Day & Date & 1 & 2 & 3 & 4 & 5 & 6 & 7 & 8 & Points & Ascending Node \\
\hline & & & & & & & & & & & \\
173 & $6 / 22$ & 2 & $2+$ & $1+$ & 1 & $1+$ & $1+$ & $1-$ & $2-$ & 1135 & 14.2 \\
174 & $6 / 23$ & $2-$ & 1 & $1+$ & $2+$ & $3-$ & $2+$ & $1+$ & $1-$ & 5154 & 14.1 \\
179 & $6 / 28$ & 2 & 2 & 3 & $2+$ & $2-$ & $2-$ & 1 & 1 & 1513 & 13.8 \\
180 & $6 / 29$ & $1-$ & 3 & $3-$ & $2-$ & $2+$ & $2-$ & $2+$ & 1 & 5457 & 13.7 \\
& & & & & & & & & & & \\
192 & $7 / 11$ & $2-$ & 2 & 2 & $1+$ & $1+$ & 1 & 3 & $1+$ & 3743 & 12.9 \\
208 & $7 / 27$ & 1 & $2+$ & 2 & $3-$ & $2-$ & $2+$ & 3 & $2+$ & 3157 & 11.9 \\
& & & & & & & & & & & \\
213 & $8 / 1$ & 1 & $2-$ & $3+$ & $2+$ & 5 & $4+$ & 5 & $5-$ & 1626 & 11.5 \\
214 & $8 / 2$ & $3+$ & $3-$ & $3-$ & $2-$ & $2-$ & 1 & $1+$ & $3-$ & 5238 & 11.5 \\
218 & $8 / 6$ & $2-$ & 2 & 2 & $2-$ & $1+$ & $3-$ & $3+$ & $2+$ & 4590 & 11.2 \\
219 & $8 / 7$ & $2+$ & $2-$ & $1+$ & $2-$ & 2 & $2-$ & 2 & $2+$ & 1464 & 11.1 \\
222 & $8 / 10$ & $1-$ & 1 & 1 & $2-$ & $2-$ & $1+$ & $2+$ & $3-$ & 3823 & 10.9 \\
223 & $8 / 11$ & $3+$ & $2-$ & $2+$ & $2-$ & $2+$ & 2 & $1+$ & $2+$ & 1229 & 10.9 \\
237 & $8 / 25$ & $1+$ & $1+$ & $1+$ & $1-$ & $1+$ & 2 & $2+$ & $3-$ & 6060 & 9.9
\end{tabular}

Table 2. Statistics of POGS data for each selected day versus $\operatorname{GSFC}(8 / 91)$

\begin{tabular}{lllll} 
Day & Date & Polnts & $\begin{array}{l}\text { Residual } \\
\text { Mean }\end{array}$ & $\begin{array}{l}\text { Residual } \\
\text { Sigma }\end{array}$ \\
\hline 173 & $6 / 22$ & 1050 & 15.8 & 26.9 \\
174 & $6 / 23$ & 4885 & 14.4 & 33.2 \\
179 & $6 / 28$ & 1494 & 13.7 & 20.9 \\
180 & $6 / 29$ & 5178 & 11.1 & 27.8 \\
192 & $7 / 11$ & 3584 & -4.7 & 34.6 \\
208 & $7 / 27$ & 2977 & -5.5 & 30.7 \\
213 & $8 / 1$ & 1487 & -23.9 & 34.5 \\
214 & $8 / 2$ & 4850 & -12.8 & 28.3 \\
218 & $8 / 6$ & 4162 & -6.2 & 20.5 \\
219 & $8 / 7$ & 1369 & -4.5 & 19.2 \\
222 & $8 / 10$ & 3608 & -6.9 & 19.7 \\
223 & $8 / 11$ & 1180 & -2.6 & 24.9 \\
237 & $8 / 25$ & 5825 & 4.7 & 26.7 \\
& & & & \\
& Total & 41649 & -0.03 & 29.6
\end{tabular}


TABLE 3: CANDIDATE IGRF MODELS

\begin{tabular}{cll}
$\begin{array}{c}\text { Model } \\
\text { Designation }\end{array}$ & $\begin{array}{c}\text { Submitting } \\
\text { Institute }\end{array}$ & $\begin{array}{c}\text { Submitting } \\
\text { Authors }\end{array}$ \\
\hline BN & BGS/NOO & $\begin{array}{l}\text { Barraclough and Quinn } \\
\text { Langel et a1. }\end{array}$ \\
GD & GSFC & Langel et al. \\
IZ & GSFC & Bondar and Golovkov \\
US & IZMIRAN & Peddie \\
\hline
\end{tabular}

BGS/NOO: Joint submission by the British Geological Survey, Edinburgh Scotland, and the U.S. Naval Oceanographic office, Stennis Space Center, MS., USA

GSFC: Goddard Space Flight Center, Greenbelt Md., USA

IZMIRAN: Institute of Terrestrial Magnetism, Ionosphere and Radio Wave Propagation, Moscow, USSR.

USGS: United States Geological Survey, Denver Co., USA.

Table 4. POGS data statistics versus candidate IGRF models

\begin{tabular}{llll} 
Model & $\begin{array}{l}\text { Residual } \\
\text { Mean }\end{array}$ & $\begin{array}{l}\text { Residual } \\
\text { RMS }\end{array}$ & $\begin{array}{l}\text { Residual } \\
\text { Sigma }\end{array}$ \\
\hline G* & -51.4 & 65.5 & 40.6 \\
GD $\star$ & -43.9 & 61.4 & 42.9 \\
BN & -56.5 & 74.6 & 48.8 \\
US & -47.9 & 64.1 & 42.5 \\
IZ & -56.6 & 73.1 & 46.2
\end{tabular}


Table 5

Model, Poos Initiel model frem 15 quibt dove

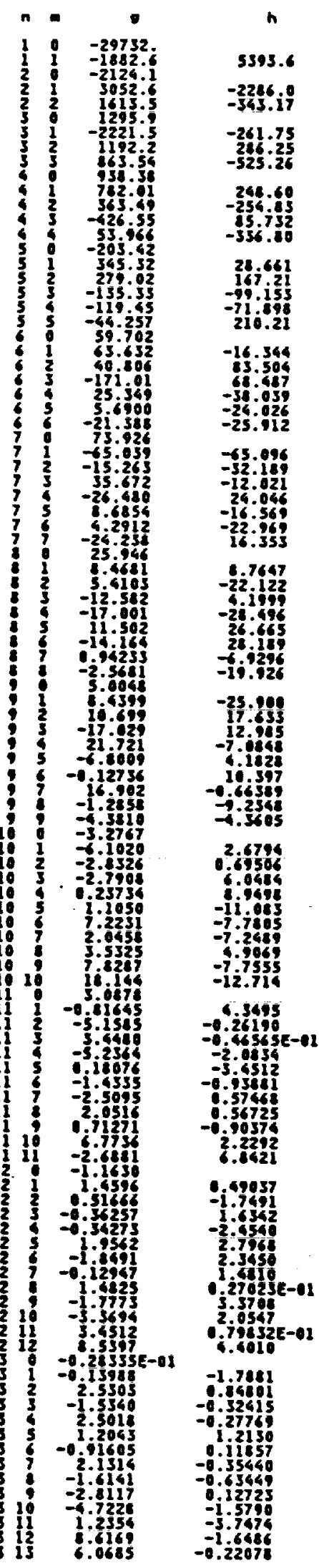


Table 6

DIFFERENCE GSFC(8/91)t - IGRF90

\begin{tabular}{|c|c|c|c|c|c|}
\hline$n$ & m & 8 & $\mathbf{h}$ & $\dot{8}$ & $\dot{\mathrm{h}}$ \\
\hline 1 & 0 & 48.4100 & 0.0000 & 1.9792 & 0.0000 \\
\hline 1 & 1 & -38.0100 & -6.8600 & 0.4316 & 0.0712 \\
\hline 2 & 0 & 13.8100 & 0.0000 & -0.0821 & 0.0000 \\
\hline 2 & 1 & -9.2300 & -4.3400 & 0.6035 & -1.2195 \\
\hline 2 & 2 & 3.7800 & 3.0300 & 1.0289 & -1.2108 \\
\hline 3 & 0 & -18.5800 & 0.0000 & 0.6711 & 0.0000 \\
\hline 3 & 1 & 20.1900 & 24.5000 & -0.3323 & -0.4210 \\
\hline 3 & 2 & -7.5700 & -6.2700 & -0.0619 & 0.4235 \\
\hline 3 & 3 & 11.4600 & -47.5300 & 0.8633 & 0.5554 \\
\hline 4 & 0 & -3.8700 & 0.0000 & 0.5191 & 0.0000 \\
\hline 4 & 1 & -1.2800 & 0.9200 & 0.3882 & 0.4405 \\
\hline 4 & 2 & 0.1300 & -0.4700 & -0.9819 & 0.1827 \\
\hline 4 & 3 & -1.2700 & -11.0300 & -0.5448 & 0.9028 \\
\hline 4 & 4 & 1.3400 & -10.6200 & 0.5354 & 0.3785 \\
\hline 5 & 0 & 8.0300 & 0.0000 & -0.6309 & 0.0000 \\
\hline 5 & 1 & -9.5100 & -16.1700 & 0.1377 & 0.1195 \\
\hline 5 & 2 & 4.2100 & -11.5300 & -0.3685 & 0.5390 \\
\hline 5 & 3 & -8.2200 & 23.4500 & -0.8843 & -0.4491 \\
\hline 5 & 4 & 9.5800 & 0.2300 & 0.0665 & 0.3401 \\
\hline 5 & 5 & -3.9600 & 9.3300 & 0.6835 & -0.4084 \\
\hline 6 & 0 & 1.3100 & 0.0000 & 0.7131 & 0.0000 \\
\hline 6 & 1 & 2.0600 & -6.2200 & -0.8179 & -0.2464 \\
\hline 6 & 2 & -1.3600 & -5.7300 & 0.1885 & 0.3475 \\
\hline 6 & 3 & 3.5100 & 3.7100 & 0.6879 & 0.0038 \\
\hline 6 & 4 & -3.0400 & 1.4800 & -0.8281 & -0.1188 \\
\hline 6 & 5 & -5.7100 & -2.7900 & -0.1272 & 0.5478 \\
\hline 6 & 6 & 9.2600 & -25.8500 & 0.8416 & -0.2244 \\
\hline 7 & 0 & -3.5600 & 0.0000 & 0.4107 & 0.0000 \\
\hline 7 & 1 & 0.1900 & 12.0800 & 0.5068 & 0.3837 \\
\hline 7 & 2 & -0.7100 & -4.7000 & 0.3072 & -0.1912 \\
\hline 7 & 3 & -2.5500 & -4.5900 & 0.3733 & 0.2277 \\
\hline 7 & 4 & -7.9400 & 4.5700 & 0.4112 & -0.4794 \\
\hline 7 & 5 & -2.7400 & -5.3800 & -0.1732 & 0.2221 \\
\hline 7 & 6 & -3.7700 & -0.3700 & -0.1707 & -0.0441 \\
\hline 7 & 7 & -15.5400 & 11.9600 & -0.2929 & 0.0343 \\
\hline 8 & 0 & 1.5900 & 0.0000 & -0.1656 & 0.0000 \\
\hline 8 & 1 & 0.8600 & 1.2600 & -0.3237 & 0.4875 \\
\hline 8 & 2 & -3.1200 & 0.9300 & 0.1716 & 0.2082 \\
\hline 8 & 3 & 1.7600 & -3.0900 & -0.1426 & 0.6717 \\
\hline 8 & 4 & 2.3700 & 0.1000 & 0.1277 & 0.7143 \\
\hline 8 & 5 & 4.2100 & 3.1300 & 0.0394 & -0.3742 \\
\hline 8 & 6 & -1.7800 & 10.0000 & 0.0532 & -0.5415 \\
\hline 8 & 7 & -0.6400 & -0.9900 & -0.5157 & 0.3154 \\
\hline 8 & 8 & -2.9800 & -18.3100 & -0.3947 & -0.6031 \\
\hline
\end{tabular}


Table 6 Continued

\begin{tabular}{rrrrrl}
$\mathbf{n}$ & $\mathbf{m}$ & \multicolumn{1}{c}{$\mathbf{g}$} & \multicolumn{1}{c}{$\mathbf{h}$} & $\mathbf{g}$ & $\mathbf{h}$ \\
\hline 9 & 0 & -0.4500 & 0.0000 & 0.0000 & 0.0000 \\
9 & 1 & -2.9200 & -1.1900 & 0.0000 & 0.0000 \\
9 & 2 & 2.2200 & 1.6200 & 0.0000 & 0.0000 \\
9 & 3 & -3.9800 & 4.4900 & 0.0000 & 0.0000 \\
9 & 4 & 4.7100 & -3.2900 & 0.0000 & 0.0000 \\
9 & 5 & -3.1300 & 3.3900 & 0.0000 & 0.0000 \\
9 & 6 & -0.6000 & 4.4500 & 0.0000 & 0.0000 \\
9 & 7 & 4.6600 & -0.1100 & 0.0000 & 0.0000 \\
9 & 8 & -5.5300 & -13.4100 & 0.0000 & 0.0000 \\
9 & 9 & 20.5300 & -4.9000 & 0.0000 & 0.0000 \\
10 & 0 & 1.6200 & 0.0000 & 0.0000 & 0.0000 \\
10 & 1 & -0.1200 & -0.2800 & 0.0000 & 0.0000 \\
10 & 2 & -2.3800 & -0.4000 & 0.0000 & 0.0000 \\
10 & 3 & 1.3200 & 3.8800 & 0.0000 & 0.0000 \\
10 & 4 & 0.3600 & 1.3800 & 0.0000 & 0.0000 \\
10 & 5 & -3.3800 & 0.1600 & 0.0000 & 0.0000 \\
10 & 6 & 0.0000 & -2.5200 & 0.0000 & 0.0000 \\
10 & 7 & 0.8200 & 0.4600 & 0.0000 & 0.0000 \\
10 & 8 & 12.8400 & -0.7600 & 0.0000 & 0.0000 \\
10 & 9 & 8.1000 & -2.5200 & 0.0000 & 0.0000 \\
10 & 10 & -2.0200 & -7.7800 & 0.0000 & 0.0000
\end{tabular}


FIGURE CAPTIONS

Figure 1: Geographic distribution of POGS data selected from quiet days.

Figure 2: Correction in time applied to the POGS data.

Figure 3: Residual of the fleld magnitude of POGS data relative to the GSFC(8/91) spherical harmonic model. This model is derived from the POGS data itself.

Figure 4: Geomagnetic field spectrum. $R_{n}$ is the total mean square contribution to the vector field by all harmonics of degree $n$. 


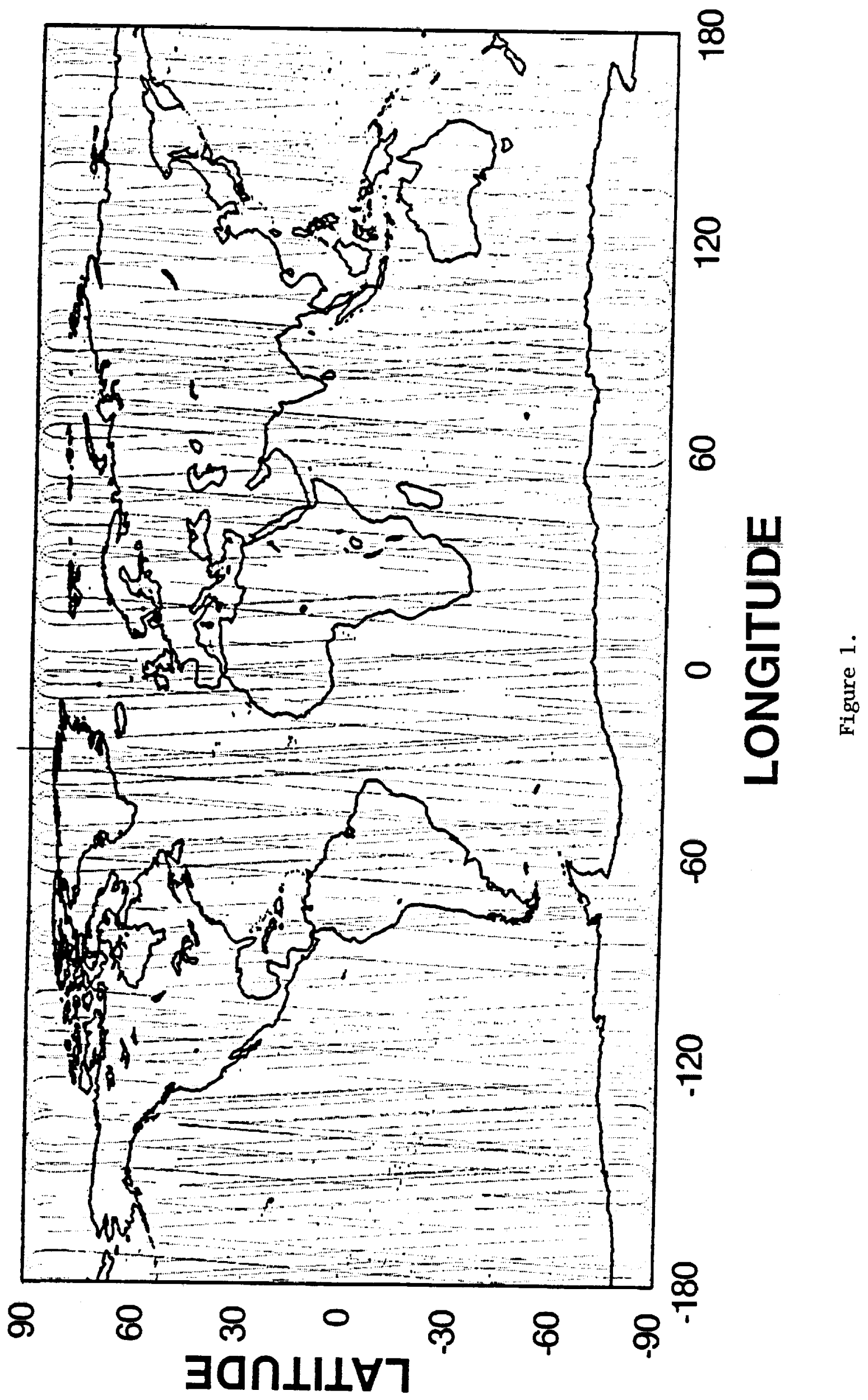




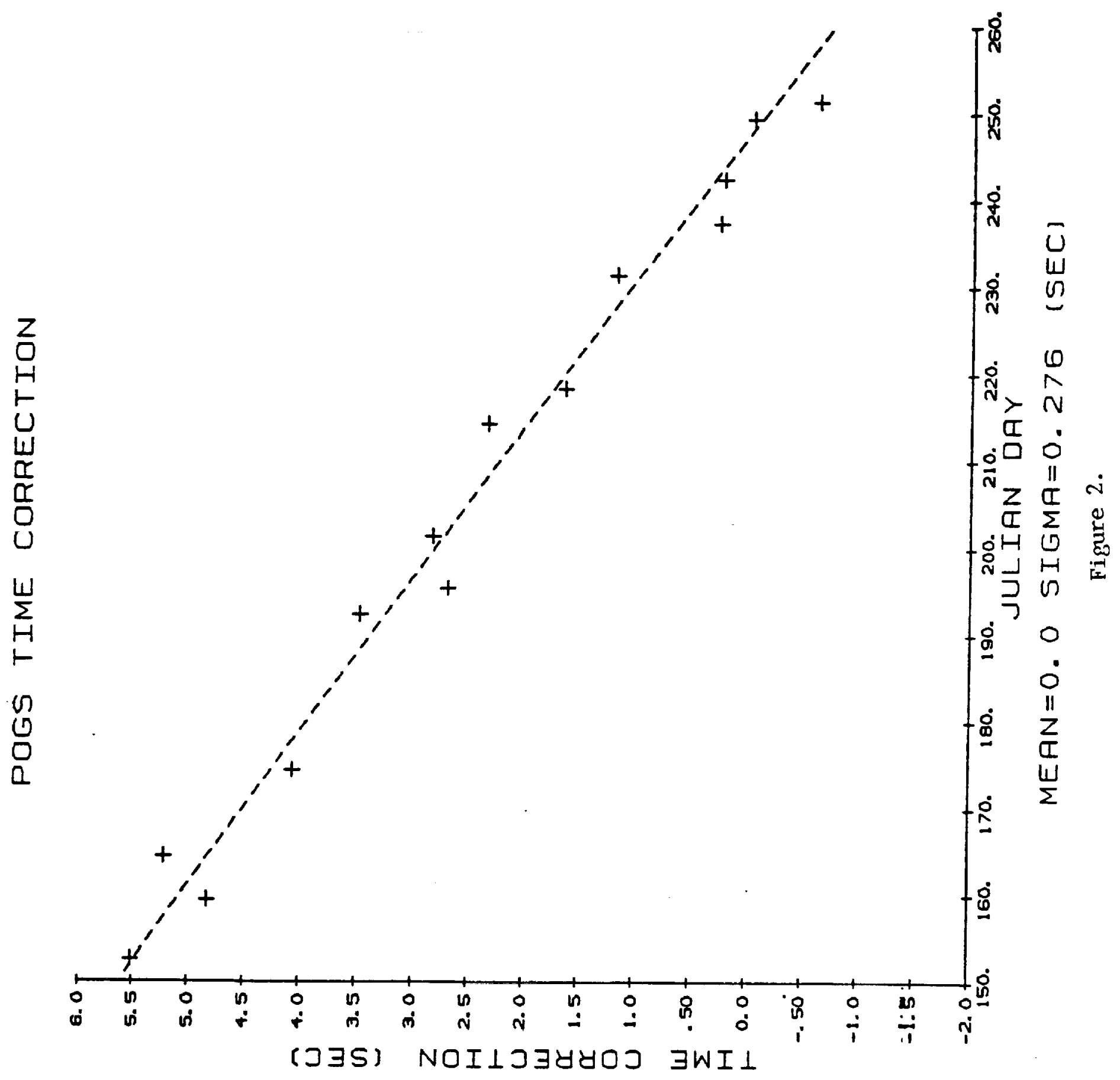




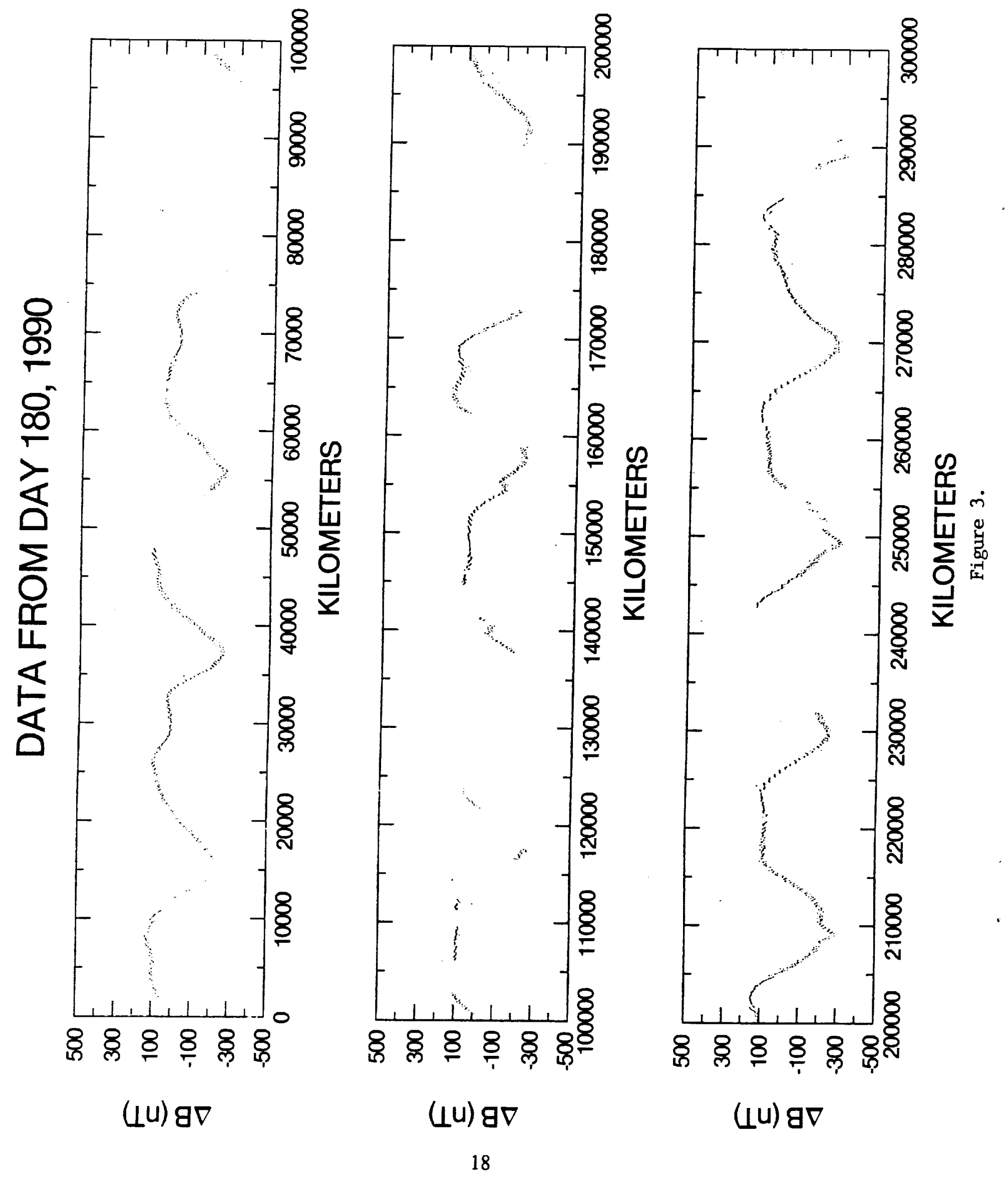




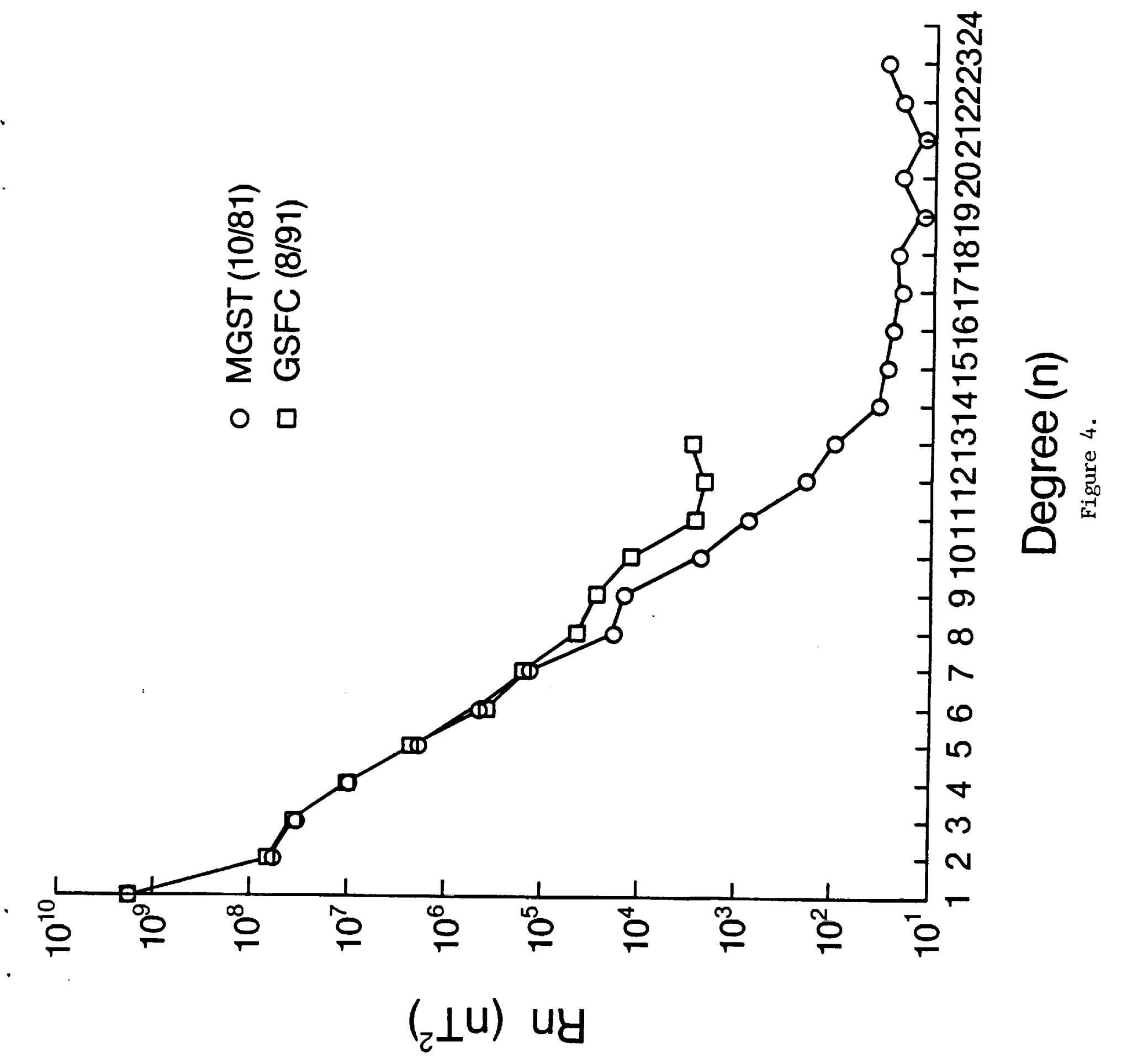


Public reporting burden lor this collection of information sestimated to averape i hour per response, including the lime for reviewing insiructions, searching existing data sources. gathering and and maintaining the dall now intormation, including suggestions for reducing this burden, to Wast ang: Budget, Papenwork Reduction Project (0704-0188), Washington. DC 20503.

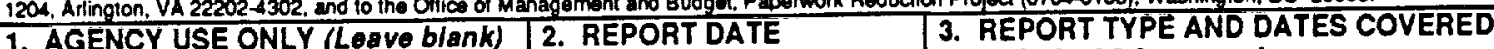

\begin{tabular}{l|l|l} 
October 1991 & Technical Memorandum \\
\hline
\end{tabular}

4. TITLE AND SUBTITLE

An Initial Analysis of the Data From the Polar Orbiting Geophysical (POGS) Satellite
5. FUNDING NUMBERS

JON 920-030-09-0101

\section{AUTHOR(S)}

R.A. Langel, T.J. Sabaka, and R.T. Baldwin

7. PERFORMING ORGANIZATION NAME(S) AND ADDRESS(ES)

NASA-Goddard Space Flight Center

Greenbelt, Maryland 20771
8. PERFORMING ORGANIZATION REPORT NUMBER

92E00297

10. SPONSORINGMONITORING AGENCY REPORT NUMBER

TM 104551

National Aeronautics and Space Administration

Washington, D.C. 20546-0001

\section{SUPPLEMENTARY NOTES}

R.A. Langel: NASA/GSFC, Code 921, Greenbelt, Maryland 20771;

T.J. Sabaka and R.T. Baldwin: ST Systems Corporation, Lanham, Maryland 20706.

12a. DISTRIBUTION/AVAILABILITY STATEMENT

12b. DISTRIBUTION CODE

Unclassified - Unlimited

Subject Category 46

\section{ABSTRACT (Maximum 200 words)}

The POGS (Polar Orbiting Geophysical Satellite) was launched in 1990 to measure the geomagnetic field. POGS data from selected magnetically quiet days was selected, quality checked and deleted where thought to be erroneous. A time-andposition correction was applied. The resulting data was fit to a degree 13 spherical harmonic model. Evaluation of the quality of the data indicates that it is sufficient for definition of the low-degree (say, less than 8) portion of the geomagnetic field. Further correction of the data time and position may improve this quality.

\section{SUBJECT TERMS}

15. NUMBER OF PAGES

Satellite Magnetic Field Measurements, Earth's Magnetic Field, Spherical Harmonic Analysis

17. SECURITY CLASSIFICATION OF REPORT

Unclassified

\section{SECURITY CLASS
OF THIS PAGE \\ Unclassified}

SECURITY CLASSIFICATION
OF ABSTRACT
Unclassified

19

16. PRICE CODE

20. UMITATION OF ABSTRACT 